\title{
Erratum to: Defining Genera of New World Monkeys: The Need for a Critical View in a Necessarily Arbitrary Task
}

\author{
Guilherme Siniciato Terra Garbino ${ }^{1,2,3}$
}

Published online: 14 December 2015

(C) Springer Science+Business Media New York 2015

\section{Erratum to: Int J Primatol \\ DOI 10.1007/s10764-015-9882-9}

The original version of this article unfortunately contained mistakes in the Introduction and Table 1. The changes are underlined as follows:

Introduction, second sentence:

First, it differs from all more inclusive categories (family group names and above) by appearing in the scientific name of a species (Mayr 1943), which is formed by a specific epithet and a generic substantive (Dubois 2000).

The online version of the original article can be found at http://dx.doi.org/10.1007/s10764-015-9882-9.

Guilherme Siniciato Terra Garbino gstgarbino@hotmail.com

1 Pós-graduação em Zoologia, Universidade Federal de Minas Gerais, 31270-901 Belo Horizonte, Minas Gerais, Brazil

2 IPÊ - Instituto de Pesquisas Ecológicas, 12960-000 Nazaré Paulista, São Paulo, Brazil

3 Pós-graduação, Museu de Zoologia, Universidade de São Paulo, 04263-000 São Paulo, SP, Brazil 


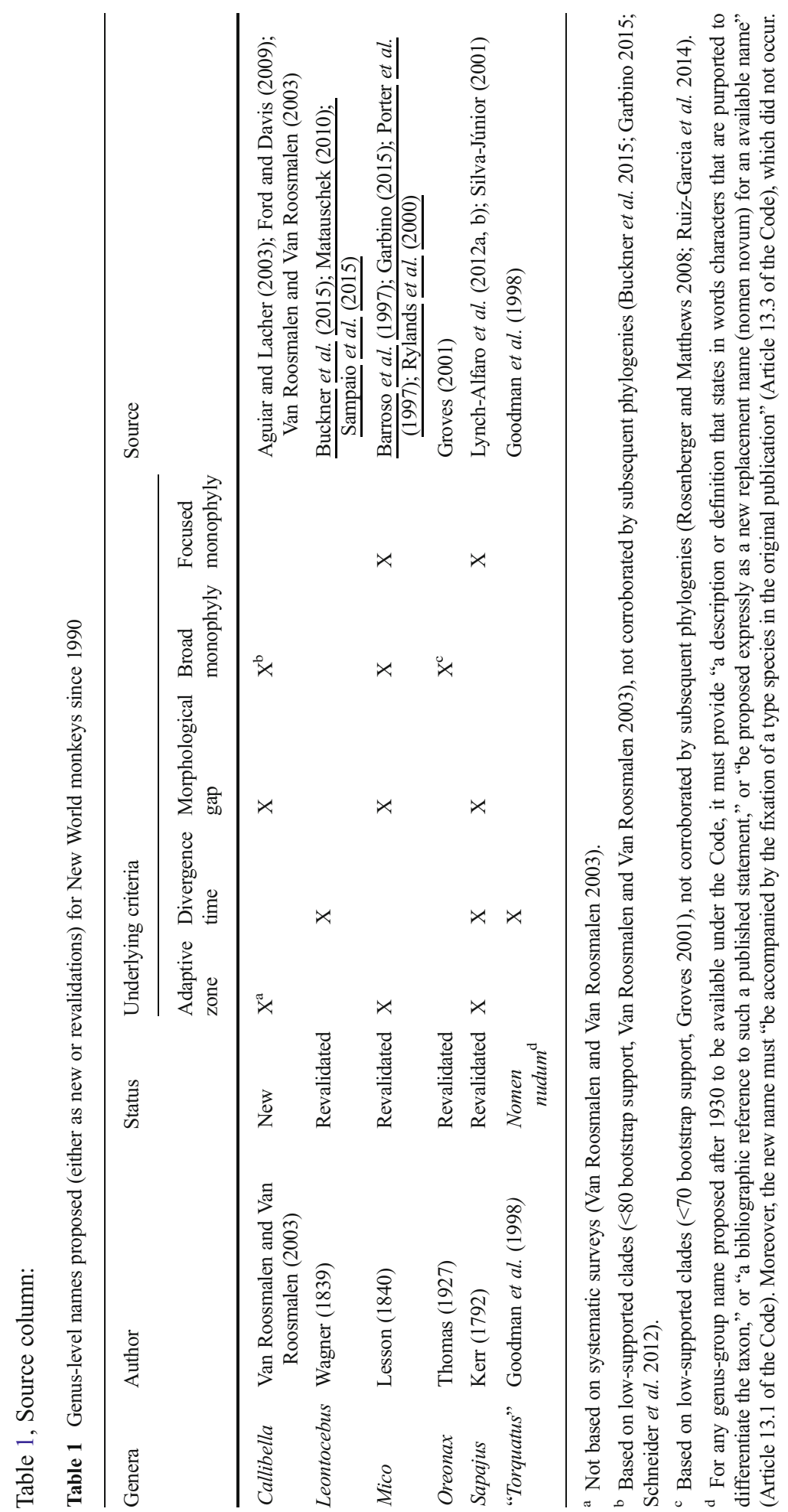

